Jurnal Sistim Informasi dan Teknologi
https://jsisfotek.org/index .php

\title{
Sistem Informasi Administrasi Pembayaran Sumbangan Pembinaan Pendidikan (SPP) Berbasis Whatsapp Gateway
}

\author{
Ogi Saputra ${ }^{1 凶}$, Wifra Safitri² \\ 1,2Universitas Putra Indonesia YPTK Padang \\ ogisaputra08092000@gmai1.com
}

\begin{abstract}
An information system is already a necessity by a school in running a better administrative system. The administrative information system using information technology with the help of computers is very helpful in the smooth operation of the school. One of the school's operations that is the principal for supporting operations is the payment of Educational Development Contributions (SPP). A more effective and efficient tuition payment procedure can streamline all school operational activities. This study aims to improve the administration of tuition payments with a whatsapp gateway-based system. This system can perform all SPP payment procedures on a mobile or mobile basis. The data processed in this study were sourced from the administration system for paying tuition fees at Mukomuko High School (SMA). The system uses PHP programming language tools and MySQL database. The result of this research is a computerized SPP payment administration system. So that the school administration can control tuition payments more effectively and efficiently. So that this system is very precise and fast in the administration of tuition payments and becomes a reference for other administrations in order to assist the administrative process and improve time efficiency and provide the right information.
\end{abstract}

Keywords: Information Systems, Administration, Payments, Educational Development Contributions (SPP), Whatsapp Gateway.

\begin{abstract}
Abstrak
Sistem informasi sudah merupakan suatu kebutuhkan oleh sebuah sekolah dalam menjalankan sistem administrasi yang lebih baik. Sistem informasi administrasi menggunakan teknologi informasi dengan bantuan komputer sangat membantu dalam kelancaran operasional sekolah. Salah satu operasional sekolah yang menjadi pokok untuk menunjang operasional adalah pembayaran Sumbangan Pembinaan Pendidikan (SPP). Prosedur pembayaran SPP yang lebih efektif dan efisien dapat mempelancar segala kegiatan operasional sekolah. Penelitian ini bertujuan meningkatkan admistrasi pembayaran SPP dengan sistem berbasis whatsapp gateway. Sistem ini dapat melakukan semua prosedur pembayaran SPP secara mobile atau bergerak. Data yang diolah dalam penelitian ini bersumber dari sistem administrasi pembayaran SPP pada Sekolah Menengah Atas (SMA) Mukomuko. Sistem menggunakan alat bantu bahasa pemrograman PHP dan database MySQL. Hasil dari penelitian ini adalah sistem administrasi pembayaran SPP secara terkomputerisasi. Sehingga administrasi sekolah dapat mengontrol pembayaran SPP lebih efektif dan efisien. Sehingga sistem ini sangat tepat dan cepat dalam administrasi pembayaran SPP dan menjadi rujukan untuk administrasi lainya agar dapat membantu proses administrasi dan meningkatkan efisiensi waktu serta memberikan informasi yang tepat.
\end{abstract}

Kata kunci: Sistem Informasi, Administrasi, Pembayaran, Sumbangan Pembinaan Pendidikan (SPP), Whatsapp Gateway.

(C) 2021 JSisfotek

\section{Pendahuluan}

Sistem informasi saat ini merupakan salah satu hal terpenting dalam suatu organisasi, instansi maupun di Sistem administrasi digunakan dalam melakukan dunia pendidikan. Kebutuhan informasi yang tepat, pembayaran yang merupakan iuran rutin sekolah dalam cepat dan akurat sangatlah dibutuhkan. Bagian dari pembayaran dilakukan setiap bulan [2]. Pembayaran informasi dalam administrasi merupakan kebutuahan SPP merupakan faktor utama untuk menjaga pokok dalam menjalankan sebuah organisai.

Sekolah Menengah Atas Negeri (SMAN) 10 Mukomuko merupakan sebuah organisasi berupa kredibilitas sekolah serta dapat memperlancar pembiayaan kegiatan belajar mengajar dan juga mendukung fasilitas sekolah [3].

sebuah sekolah yang sangat membutuhkan sistem Sistem administrasi SPP harus dapat dipantau setiap administrasi. Sistem administrasi ini berfungsi saat, maka diperlukan suatu media komunikasi yang mengatur semua urusan yang berhubungan dengan selalu aktif setiap saat dan dimana saja. Salah satu kegiatan sekolah. Salah satu administrasi pokok adalah aplikasi yang mendukung ini adalah Whatsapp (WA). pembayaran Sumbangan Pembinaan Pendidikan (SPP). WA dapat dimanfaatkan untuk berkomunikasi dan Sistem dalam SPP merupakan administrasi yang menyampaikan pesan kepada seseorang yang akan merupakan proses dalam dalam organisasi untuk dituju sestiap saat [4]. Dalam meningkatkan efektif dan 
efisiensi harus didukung dengan peralatan komputer Sistem whatsapp gateway dibantu dengan perancangan dan berbasis whatsapp gateway. Whatsapp gateway UML (Unified Modelling Language). UML merupakan merupakan sistem pemberitahuan dalam mengirim pemodelan standar dalam mengembangkan sistem pesan pemberitahuan kepada seseorang [5].

Pesan pemberitahuan atau pengingat pembayaran SPP yang selama ini sedang berjalan pada SMAN 10 Mukomuko masih penyampaian pesan secara langsung oleh guru kepada siswa. Pesan yang dikirimkan secara langsung sering tidak terperhatikan oleh siswa, sehingga siswa sering terlambat dalam melakukan proses pembayaran SPP [6].

Whatsapp gateway merupakan teknologi pengiriman pesan yang dimanfaatkan sebagai media pengiriman pesan terhadap informasi tentang pembayaran SPP. Pesan juga dapat langsung disampaikan kepada wali murid karena hampir sebagian besar orang tua murid menggunakan Whatsapp dalam komunikasi. Sistem ini efektif digunakan dibandingkan dengan menggunakan SMS gateway [7].

Sistem administrasi ini diharapkan agar para orang tua dengan cepat mendapatkan informasi. Guru tidak perlu mengingatkan para siswa untuk melakukan pembayaran SPP, karena sumber dana pembayarannya adalah orang tua siswa. Sistem seperti ini berfungsi mengurangi kesalahan informasi. Sistem teknologi Whatsapp gateway berguna untuk memudahkan memberi informasi ke wali murid. Pembayaran SPP ini merupakan hal yang sangat penting dalam menjaga kestabilan proses pembelajarannya [8].

Administrasi merupakan serangkaian kegiatan yang berupa proses pengaturan usaha kerjasama manusia untuk mencapai tujuan bersama yang telah ditetapkan sebelumnya [9]. Pembayaran adalah hal yang dilakukan dalam kegiatan administrasi pembayaran ini juga merupakan aspek penting dalam suatu proses administrasi. Pembayaran dimaksudkan kegiatan penting dalam menunjang kegiatan pembelajaran dan operasional sekolah [10].

Administrasi pembayaran ini merupakan suatu kegiatan administrasi yang melakukan semua pembayaran di lembaga pendidikan baik formal maupun non formal agar berlangsung secara efektif dan efisien dalam mencapai tujuannya. Administrasi pembayaran merupakan suatu kegiatan yang membantu dalam layanan pembayaran pada kegiatan administrasi sekolah [11].

SPP merupakan biaya yang dibebankan kepada siswa yang harus dibayar per bulan selama menjadi siswa [12]. Setiap siswa yang masih aktif di sekolah berkewajiban dalam membayar SPP yang ada di penelitian dan manfaat penulisan, tujuan umum sekolah tersebut. Pembayaran SPP ditentukan organisasi, struktur organisasi, serta deskripsi tugas berdasarkan kesepakatan rapat guru sekolah dan orang masing-masing bagian dalam organisasi dan tua siswa [13]. SPP ditujukan untuk meningkatkan mengindentifikasi permasalahan yang ada.

mutu pendidikan yang terkait sarana dan prasarana kegiatan belajar mengajar di sekolah. berorientasi objek dan juga merupakan alat untuk mendukung pengembangan sistem. Pemodelan sesungguhnya digunakan untuk penyederhanaan permasalahan yang kompleks sedemikian rupa sehingga lebih mudah dipelajari dan dipahami [14]. Sistem Whatsapp dapat mengirimkan informasi baik berupa text, video dan lainnya yang dimiliki perusahaan meta.

\section{Metodologi Penelitian}

\subsection{Kerangka penelitian}

kerangka penelitian adalah konsep suatu penelitian yang menghubungkan antara satu variabel dengan variabel lainnya, sehingga penelitian menjadi tersusun secara sistematis dan dapat diterima oleh semua pihak. Dimana kerangka penelitian yang akan dilakukan, digambarkan seperti Gambar 1.

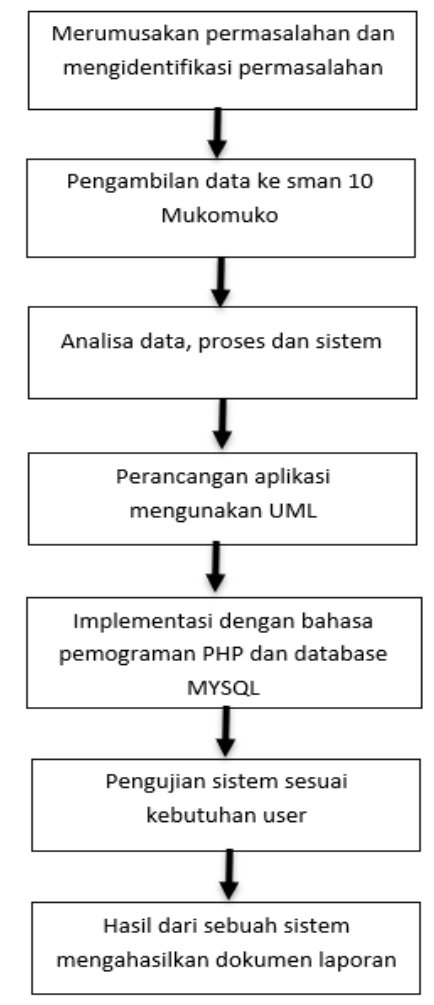

Gambar 1. Kerangka Kerja Penelitian

\subsection{Penelitian pendahuluan}

adalah Langkah awal dalam melakukan penelitian. Dalam tahap ini berisi latar belakang, ruang lingkup Dengan penelitian pendahuluan dapat memberikan bukti awal bahwa masalah yang akan kita teliti dilapangan benar benar ada. Penelitian ini dilakukan

Jurnal Sistem Informasi dan Teknologi Vol . 4 No. 1 (2022) 1-6 
dengan cara survey kelapangan dan survey data sistem. Class diagram mampu memberikan kita sebelum melakukan penelitian lebih lanjut terhadap pandangan yang lebih luas mengenai suatu sistem objek penelitian oleh sebab itu dibutuhkan waktu untuk dengan cara menunjukkan kelas serta hubunganpengambilan data, waktu penelitian, tempat penelitian, hubungannya.

metode penelitian, penelitian lapangan, riset perpustakaan.

\subsection{Pengumpulan data}

Pengumpulan data dilakukan dengan cara observasi atau terjun kelapangan secara langsung dan melakukan wawancara terhadap pihak yang bersangkutan di tempat penelitian serta memberikan pertanyaan kepada pihak sekolah SMA Negeri 10 Mukomuko untuk melakukan pengambilan data.

\subsection{Metode Penelitian}

Sequence diagram menggambarkan interaksi antar objek di dalam dan di sekitar sistem (termasuk pengguna, display, dan sebagainya) berupa message yang digambarkan terhadap waktu. Activity diagram menggambarkan workflow (aliran kerja) atau aktifitas dari sebuah sistem atau proses bisnis. Deployment diagram menunjukan konfigurasi komponen dalam proses eksekusi aplikasi. Sebuah node adalah server, workstation, atau piranti keras lain yang digunakan untuk men-deploy komponen dalam lingkungan sebenarnya.

Dalam melakukan penelitian agar mendapatkan hasil 2.7. Implementasi seperti yang diharapkan, maka sekiranya diperlukan suatu metode penelitian yang biasa dilakukan yaitu:

Pada tahap ini peneliti akan membahas mengenai bahasa pemrograman yang akan dipakai. Penelitian ini

a. Penelitian Lapangan (Field Research) langsung menggunakan bahasa pemrograman PHP dimana terjun kelapangan mengambil data yang di butuhkan sistem tersebut berbasiskan web. Implementasinya untuk melakukan permintaan data dengan cara ialah kegiatan yang dilakukan dengan perencanaan dan melakukan wawancara.

b. Penelitian Pustaka (Library Research) dalam metode ini, penulis mencari sumber-sumber yang akan mendukung penelitian. mengacu kepada aturan tertentu untuk mencapai tujuan suatu kegiatan.

\subsection{Pengujian}

tahap ini melakukan uji coba yang bertujuan untuk

c. Penelitian Laboratorium (Laboratory Research) mengetahui apakah aplikasi yang di rancang dapat dalam metode ini penelitian dilakukan dengan cara berjalan dengan baik dan sesuai dengan proses menganalisa data serta merancang program atau perancangannya. Sistem yang dirancang dengan perangkat lunak yang sesuai dengan permasalahan menggunakan bahasa pemrograman PHP dan database yang dihadapi.

\subsection{Analisa}

MySQL dapat memberikan kemudahan kepada pihak SMA Negeri 10 Mukomuko dalam proses pembayaran SPP dan pemberitahuan informasi menggunakan

Analisa data adalah proses inspeksi, pembersihan dan whatsapp gateway. pemodelan data dengan tujuan menemukan informasi yang berguna, menginformasikan kesimpulan dan mendukung pengambilan keputusan.

\section{Hasil dan Pembahasan}

\subsection{Analisa sistem}

Analisa Proses dilakukan untuk mengetahui apa saja Analisa input pada sistem yang lama yaitu pihak yang dibutuhkan dalam merancang aplikasi untuk sekolah dalam pembayaran SPP SMAN 10 Mukomuko membantu pihak sekolah dalam proses pembayaran saat menggelola data pembayaran SPP secara manual SPP serta pemberitahuan informasi pembayaran.

Analisa Sistem dilakukan untuk mengetahui apa saja yang dibutuhkan dalam perancangan sistem. Sehingga menghasilkan sebuah sistem yang efektif dan efesien dalam implementasinya.

\subsection{Perancangan Aplikasi}

Perancangan sistem yang akan dijalankan menggunakan UML sebagai tools dalam menjelaskan Analisa Output yaitu berisikan output yang ada pada alur analisa program. Dimana perancangan UML itu proses sistem, sistem informasi masih berupa terdiri dari Use Case Diagram, Class Diagram, pencatatan laporan yang masih manual. Setelah Sequence Diagram, State Diagram, dan Activity melakukan tahap analisa terhadap sistem yang sedang Diagram.

Use case diagram merupakan model diagram UML yang digunakan untuk menggambarkan requirement fungsional yang diharapkan dari sebuah dimana setiap proses transaksi pembayaran dan serta bukti pembayaran siswa melakukan pencatatan dengan media kertas. Analisa Proses yang dilakukan terhadap proses yang dijalankan pada suatu informasi yang lama menunjukkan pengolahan yang tepat yang mengharuskan pegawai sekolah untuk membuat semua laporan pembayaran SPP dengan media kertas dan juga masih menggunakan dokumen sebagai arsip. berjalan saat ini dapat ditemukan kelemahan pada sistem lama terutama pada transaksi dan pembuatan laporan pembayaran SPP. Untuk mengatasi masalah yang dihadapi oleh sistem lama maka dibentuklah sistem baru. Dimana transaksi, pemberitahuan 
informasi dan pembuatan laporan pembayaran SPP dapat dilakukan oleh admin dengan pembuatan secara otomatis pada sistem aplikasi yang dibangun.

\subsection{Perancangan Sistem dan Aplikasi}

Tujuan dari desain sistem ini untuk memenuhi kebutuhan user, memberikan gambaran yang jelas kepada programmer dan pihak lain yang terlibat dalam perancangan sebuah sistem baru. Dimana perancangan sistem ini menggunakan Unified Modelling Languange $(U M L)$. Tujuan dari perancangan UML itu sendiri adalah untuk meningkatkan kerja yang efektif dan efisien dari pembayaran SPP SMAN 10 Mukomuko dan dapat meminimalkan waktu, tenaga, dan biaya.

\subsection{Use Case Diagram}

Use case menggambarkan bagaimana seseorang akan menggunakan atau memanfaatkan sistem, sedangkan aktor adalah seseorang yang berinteraksi dengan sistem. Use case Diagram menggambarkan bagaimana proses-proses yang dilakukan oleh aktor terhadap sebuah sistem. Use Case Diagram sistem aplikasi pembayaran SPP SMAN 10 Mukomuko dapat dilihat seperti Gambar 2.

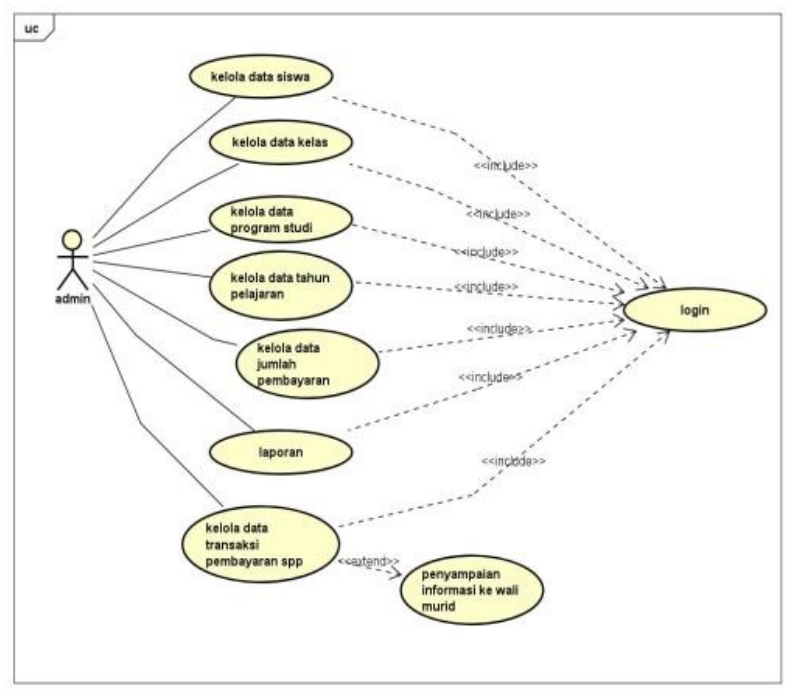

Gambar 2. Use Case Diagram Pembayaran SPP

\subsection{Class Diagram,}

Class diagram adalah sebuah spesifikasi jika diinstalasi akan menghasilkan sebuah objek dan merupakan inti dari pengembangan dan desain berorientasi objek. Adapun Class Diagram Pembayaran SPP SMAN 10 Mukomuko dapat dilihat seperti Gambar 3.

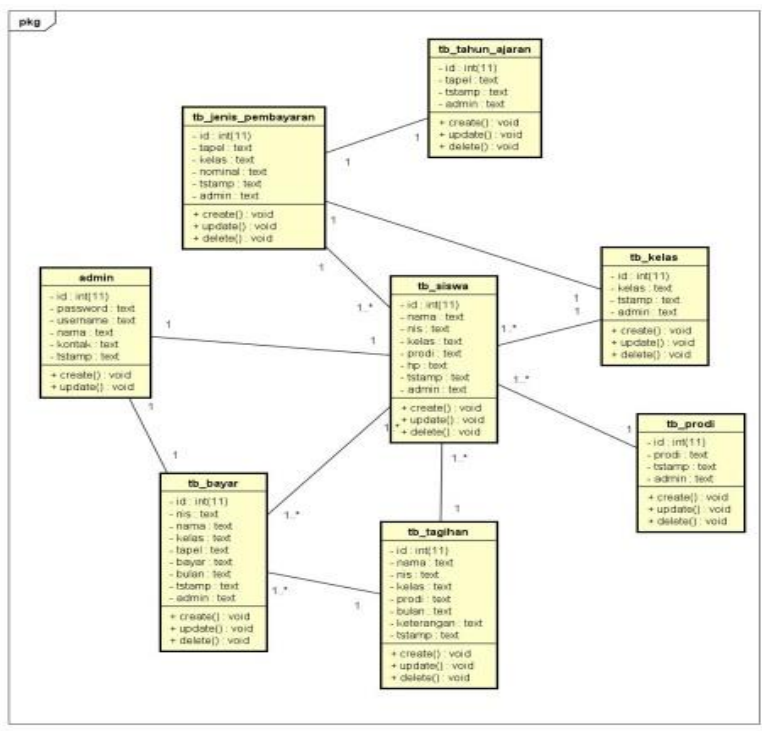

Gambar 3. Class Diagram Pembayaran SPP

\subsection{Acitivity Diagram}

Activity diagram merupakan sebuah diagram yang di dalam nya terdapat semua aktivitas dalam sistem informasi pada pembayaran SPP ini. dapat dilihat seperti Gambar 4.

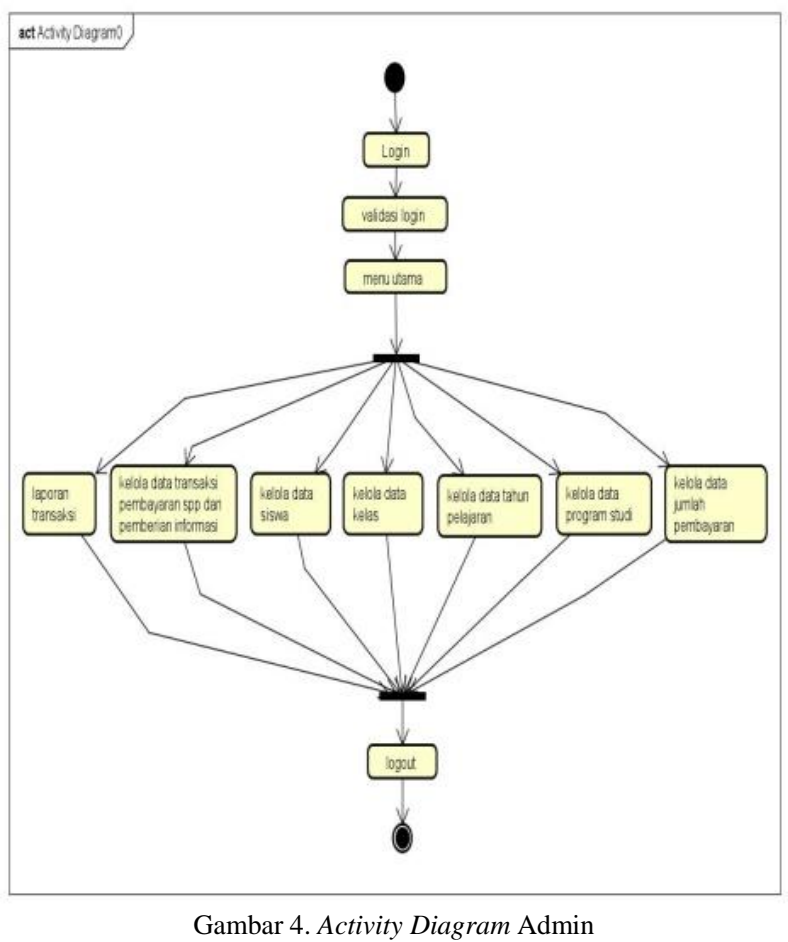

\subsection{Sequence Diagram}

Sequence diagram menjelaskan interaksi objek yang disusun berdasarkan urutan waktu. Sequence diagram transaksi pembayaran ini menjelaskan bagaimana cara admin mengelola transaksi dan juga penyampain informasi untuk melakukan pembayaran SPP, admin bisa cetak bukti pembayaran. Adapun Sequence 
Diagram dari perancangan ini dapat dilihat pada Gambar 5.

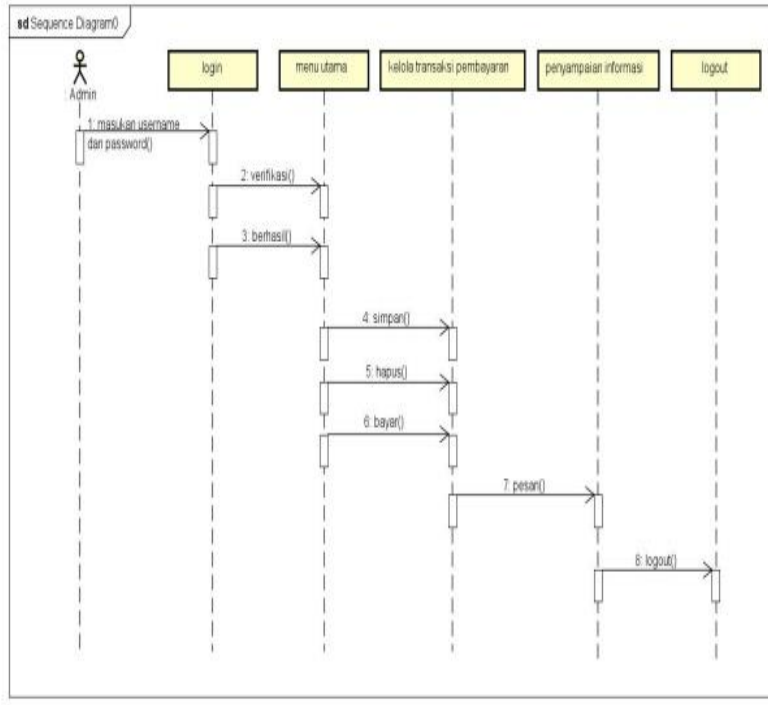

Gambar 5. Sequence Diagram Kelola Data Transaksi pembayaran

\subsection{Deployment Diagram Pembayaran SPP}

Deployment Diagram ini akan menunjukkan konfigurasi komponen di dalam proses eksekusi aplikasi. Adapun Deployment Diagram dari perancangan ini dapat dilihat pada Gambar 6.

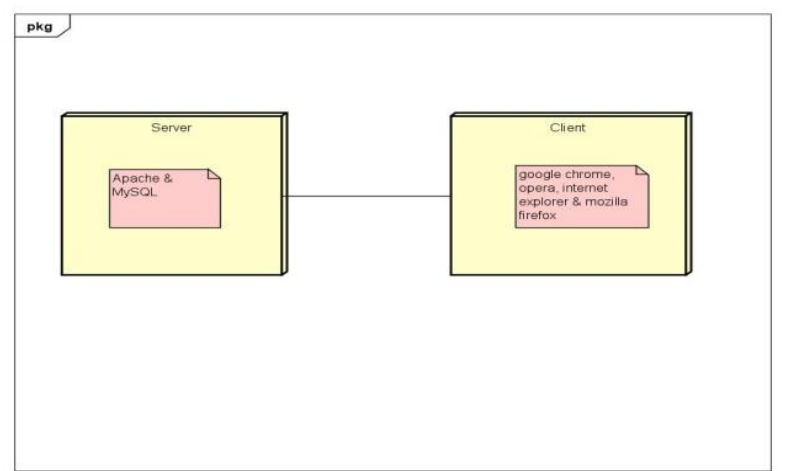

Gambar 6. Deployment Diagram Pembayaran SPP

\subsection{Implementasi Sistem}

merupakan salah satu tahap dalam pengembangan sistem, dimana tahap ini merupakan tahap meletakkan sistem informasi supaya siap untuk dipakai. Tampilan halaman menu ini menunjukan tampilan sistem secara umum ketika sudah melakukan login pada sistem terlebih dahulu. Pada halaman ini terdapat beberapa menu diantaranya menu data master yang berisi data siswa, data kelas, data program studi, tahun pelajaran, data nominal pembayaran, transaksi pembayaran, laporan. Seperti pada Gambar 7.

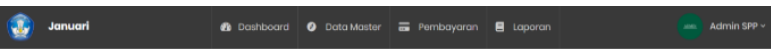

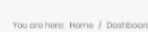

Welcome back, Admin SPP!
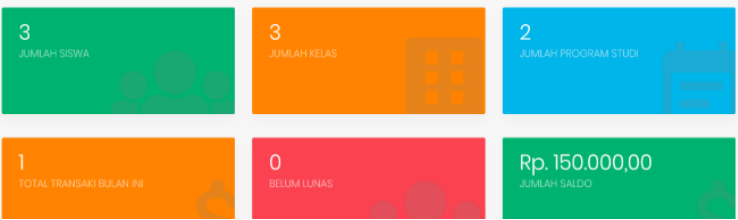

Rp. $150.000,00$

Gambar 7. Halaman Menu

Halaman Pembayaran menunjukan tampilan proses pencarian data siswa yang akan melakukan pembayaran SPP lalu melakukan pembayaran, dan pemberian informasi ke siswa melalui whatsapp. Seperti pada Gambar 8.

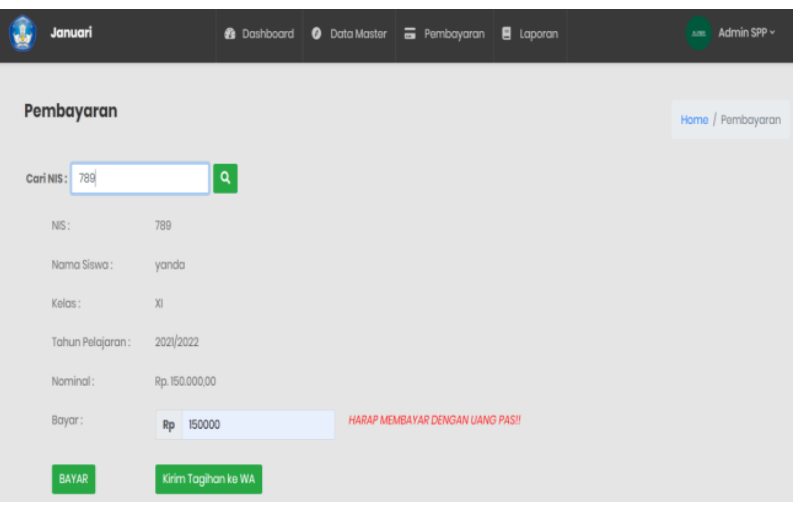

\section{Gambar 8. Halaman Pembayaran}

Halaman Pemberian Informasi Tampilan halaman pemberian informasi melalui whatsapp lalu diarahkan langsung ke nomor siswa dan pemberian pesan ke nomor siswa tersebut. Seperti pada Gambar 9.

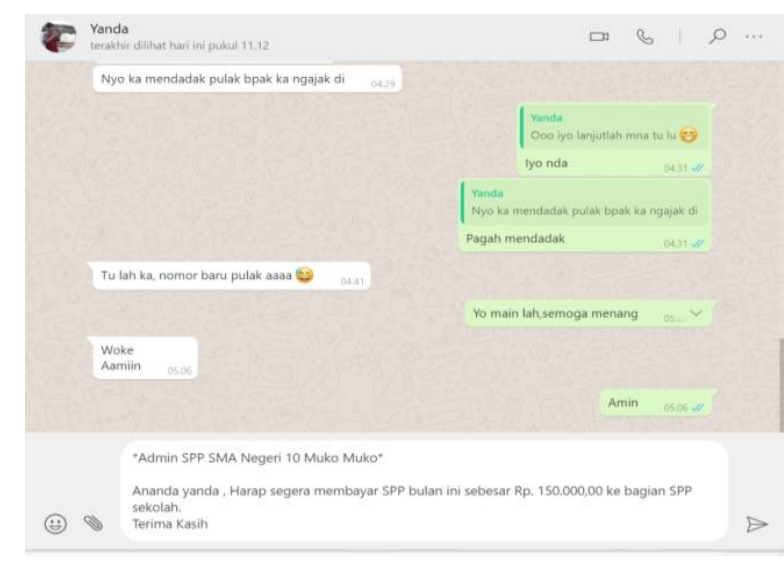

Gambar 9. Halaman Pemberian Informasi

Halaman database merupakan halaman yang digunakan untuk menyimpan data yang diinputkan kedalam sistem, seperti terlihat pada Gambar 10. 


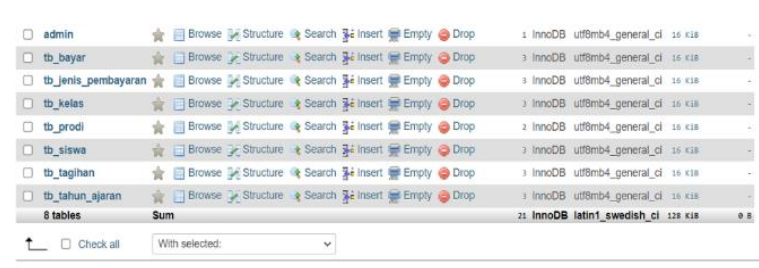

Gambar 10. Halaman Database

Halaman laporan tagihan pembayaran ini menunjukan tampilan laporan dari pembayaran yang telah dilakukan dan laporan bisa di cetak. Seperti pada Gambar 11.

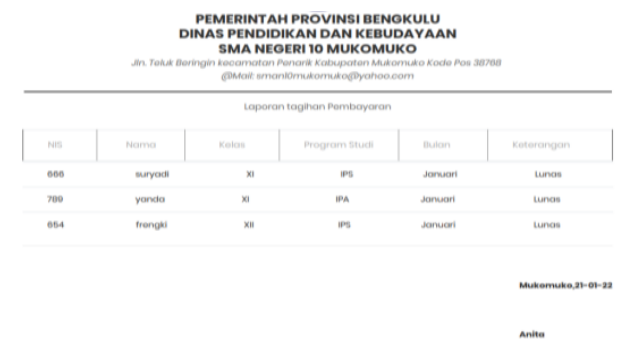

Gambar 11. Hasil Cetak Laporan Tagihan Pembayaran

Berdasarkan hasil pengujian terhadap pemantauan sistem pembayaran SPP menggunakan Whatsapp gateway, maka informasi dapat dipantau dengan cepat dan tepat. Sistem ini sangat membantu dalam meningkatkan kinerja Sistem Informasi Administarsi pembayaran SPP.

\section{Kesimpulan}

Dengan sistem administrasi pembayaran SPP ini dapat membantu pihak SMAN 10 Mukomuko mempermudah proses pembayaran SPP siswanya, Meningkatkan efisensi waktu dalam proses pembayaran SPP. Dengan sistem pembayaran SPP berbasis whatsapp gateway dapat memberikan informasi yang tepat, cepat dan akurat dalam sistem. penilitian selanjutnya untuk mengembangkan lagi sistem pembayaran SPP berbasis whatsapp gateway ini yang lebih baik karena sistem belum bisa mengirim bukti pembayaran langsung ke whatsapp siswa.

\section{Daftar Rujukan}

[1] Fitri, D. Z. (2020). Pengertian Administrasi Peserta Didik, Proses Administrasi Peserta Didik, Instrumen Administrasi Peserta Didik ( Manual \&amp; Elektronik), Dan Peran Guru Dalam Administrasi Peserta Didik. 1-4. https://doi.org/10.31219/osf.io/74wyn

[2] Pangestuti, A. S., \& Wijanarko, R. (2021). Sistem Informasi Pembayaran SPP Berbasis WEB pada SMK Muhammadiyah 11 Jakarta Pusat. Jurnal Informatika Dan Rekayasa Perangkat Lunak, 3(2), 110.https://doi.org/10.36499/jinrpl.v3i2.4603
[3] Roza, Y., Suci Rahayu Rais, N., \& Jati, A. R. (2020). Perancangan Sistem Pembayaran SPP Pada SMK Islam Iqro Pasar Kemis. Cices, 6(1), 71-79. https://doi.org/10.33050/cices.v6i1.879

[4] Siti Nur Annisa, Setiono, \& Aa Juhanda. (2021). Kemampuan Berpikir Kritis Peserta Didik Melalui Model Pembelajaran Guided Inquiry Berbasis Riset Berbantuan Media WhatsApp. JURNAL PENDIDIKAN MIPA,11(1), 18-26. https://doi.org/10.37630/jpm.v11i1.431

[5] Yulianto, S. V., Setia, L. D., \& Atmaja, A. P. (2021). The Use of Whatsapp Gateway for Automatic Notification System. Journal of Physics: Conference Series, 1845(1). https://doi.org/10.1088/1742-6596/1845/1/012014

[6] Farma, T. A., \& Okra, R. (2021). Pengembangan Aplikasi Pembayaran dan Didukung oleh Pesan WA Sebagai Notifikasi Pembayaran di SMA INS Kayutanam. JSTIE (Jurnal Sarjana Teknik Informatika) (E-Journal), 9(1). https://doi.org/10.12928/jstie.v1i1.17363

[7] Hakim, L., Kristanto, S. P., Shodiq, M. N., \& Amaliyah, E. (2021). Aplikasi Penerimaan dan Pengeluaran Kas Berbasis Web dan WhatsApp Gateway. Jurnal Tekno Kompak, 15(1), 13. https://doi.org/10.33365/jtk.v15i1.900

[8] Rustam, M. T., Sipahutar, L., \& ... (2020). Sistem Informasi Pembayaran SPP dan Absensi Siswa Berbasis SMS Gateway. Jurnal MEDIA INFORMATIKA BUDIDARMA, 4, 1033-1042. https://doi.org/10.30865/mib.v4i4.2354

[9] Setiawan, T. (2019). Analisis Perkembangan Pembayaran SPP secara Online di suatu Universitas. https://doi.org/https://doi.org/10.31219/osf.io/5bhx9

[10]Sar, I. P. (2020). Implementasi Pembayaran SPP Berbasis WEB Pada Sekolah Menengah Pertama (SMP) Muhammadiyah Kota Medan. Jurnal Pengabdian Barelang, 2(03), 11. https://doi.org/10.33884/jpb.v2i03.1986

[11]Dewi, I. R., \& Malfiany, R. (2017). Perancangan Sistem Informasi Administrasi Pembayaran Pada Sdit Lampu Iman Karawang Berbasis Visual Basic 6.0. Jurnal Interkom: Jurnal Publikasi Ilmiah Bidang Teknologi Informasi Dan Komunikasi, 12(2), 4-12. https://doi.org/10.35969/interkom.v12i2.5

[12]Azizah, N., Warid, M., \& Hidayatulloh, A. (2020). Implementasi Sistem Informasi Pembayaran SPP Berbasis Web (Studi Kasus : SMK Arrahman Tangerang). Cices, 6(1), 100-110. https://doi.org/10.33050/cices.v6i1.884

[13]Ubbaidillah, U., \& Evayani, E. (2020). Perancangan Sistem Informasi Pencatatan Pembayaran SPP Pada Pondok Pesantren Modern Tgk Chiek Oemar Diyan. Jurnal Ilmiah Mahasiswa Ekonomi Akuntansi, 5(4), 560-570. https://doi.org/10.24815/jimeka.v5i4.15760

[14]Ananda, I., \& Zuraidah, E. (2019). Perancangan Sistem Informasi Penjualan Barang Pada PT Asia Truk Pratama Jakarta. Jurnal Informatika, 6(2), 193-200. https://doi.org/10.31311/ji.v6i2.6248 